\title{
FURTHER EVIDENCE FOR EGG TRANSFORMATION IN NICOTIANA
}

\author{
K. K. PANDEY \\ Genetics Unit, Grasslands Division, DSIR, \\ Palmerston North, New Zealand
}

Received 21.ix.79

\begin{abstract}
SUMMARY
Transformation of the egg by irradiated pollen has now been achieved in all five Nicotiana species tested, using self-compatible as well as self-incompatible species as the female parent. The self-incompatibility gene $(S)$ and flower colour and pollen colour genes have been transferred in this manner. In one species combination, $N$. bonariensis $\&(n=9) \times N$. glauca $(n=12)$ of donor, the transformed progeny having an $S$ allele from the donor parent, were fertile and fully maternal in general morphology and chromosome number. Sexual hybrids are morphologically distinct from both paren ts and are completely sterile. This rules out the possibility that any pollen may have escaped the lethal dose of radiation and achieved normal fertilisation.

Transformation may occur in association with parthenogenetic diploidy, or a second, normal fertilisation by unirradiated pollen. The transferred gene may be expressed in the first (T1) generation or may be suppressed until the following sexual generation (T2). The observations suggest that a major gene closely linked with the $S$ locus promotes development of the $S$ transformed egg into a viable diploid seed, thus aiding recovery of transformed progeny. On the reasonable assumption that the $S$ locus is only one of several genes that are transformed together in one act of pseudofertilisation it is suggested that the $S$ locus may be used as a selection marker in the practical application of egg transformation in plant improvement.
\end{abstract}

\section{INTRODUCTION}

REPORTS of the occurrence in flowering plants of genetic transformation induced by donor DNA are still a matter of controversy (Cocking, 1977; Lurquin, 1977; Hess, 1977; Pandey, 1978a). ("Transformation" is broadly defined in this context as the transfer of certain genes rather than the total complement of a donor nucleus.) Recently, transformation has been achieved in Nicotiana alata and $N$. forgetiana, by a new method which does not involve extraction of the donor DNA (Pandey, 1975a, $b, 1976,1978 b$ ). In this method pollen from the compatible donor species $(\boldsymbol{N}$. alata) was treated with a high dose $(100 \mathrm{Kr})$ of ionising radiation and mixed with live pollen of the self-incompatible female parent before pollination. The small number of progeny (T1) produced by this method resembled the female parent in all but a few characters which were derived from the irradiated donor. An independent observation that single genes can be transferred from irradiated pollen to T1 progeny has recently been made by Virk et al. (1977) for $N$. rustica. An hypothesis for the molecular processes involved in egg transformation has been proposed earlier (Pandey, 1976,1978b). After the initial discovery, a new series of experiments was undertaken involving a broader range of materials in the genus Nicotiana. Results of these experiments are reported here. 


\section{MATERIALS AND MEthodS}

Description of plant materials used is given in table 1 , which also includes bud-selfed segregation data for $N$. forgetiana plants used as donors and recipients. $N$. alata, $N$. forgetiana and $N$. langsdorffi are closely related, and normal crosses between them produce fully fertile hybrids. $N$. bonariensis and $N$. glauca are relatively distantly related. Normal crosses between them produce few viable seeds, and their relatively rare hybrids are completely sterile. Numbering sequences in the $S$ allelic series of different species are independent. Different homozygous $S$ genotypes, mostly used as testers, were produced through bud pollination aided by the application of stigmatic secretion to the stigma before pollination (Pandey, 1963). Sources of most of the seed materials have been given before (Pandey, 1969, 1973, 1977). Seed of $N$. forgetiana used in the present study was kindly supplied by Dr H. Takahashi, Faculty of Agriculture, Kyoto University, Japan.

TABLE 1

Plant materials and their characteristics

\begin{tabular}{|c|c|c|c|}
\hline Species plant no. & $\begin{array}{l}\text { Incompatibility } \\
S \text { genotype }\end{array}$ & Flower colour & Pollen colour \\
\hline $\begin{array}{l}\text { N. alata* }(n=9) \\
\text { 9151-2 } \\
8541-3\end{array}$ & $\begin{array}{l}S_{\mathrm{F} 10} S_{\mathrm{F} 11} \\
S_{3} S_{3}\end{array}$ & $\begin{array}{l}\text { Homozygous white } \\
\text { Homozygous red }\end{array}$ & $\begin{array}{l}\text { Homozygous white } \\
\text { Homozygous white }\end{array}$ \\
\hline $\begin{array}{l}N \text {. forgetiana } \dagger(n=9) \\
403-1 \\
403-2 \\
403-6 \\
403-5\end{array}$ & $\begin{array}{l}S_{3} S_{5} \\
S_{4} S_{5} \\
S_{3} S_{5} \\
S_{3} S_{6}\end{array}$ & $\begin{array}{l}\text { Heterozygous coloured } \\
\text { Heterozygous coloured } \\
\text { Heterozygous coloured } \\
\text { Heterozygous coloured }\end{array}$ & $\begin{array}{l}\text { Heterozygous blue } \\
\text { Heterozygous blue } \\
\text { Heterozygous blue } \\
\text { Homozygous white }\end{array}$ \\
\hline $\begin{array}{l}N . \text { bonariensis }(n=9) \\
9587-13\end{array}$ & $S_{12} S_{13}$ & Homozygous white & Homozygous white \\
\hline $\begin{array}{l}\text { N. glauca }(n=12) \\
8468-10\end{array}$ & $S_{2} S_{9}$ & Homozygous red & Homozygous white \\
\hline $\begin{array}{l}\text { N. langsdorffii }(n=9) \\
\text { Self-compatible }\end{array}$ & & Homozygous green & Homozygous blue \\
\hline
\end{tabular}

* $S$-homozygous testers $S_{\mathrm{F} 10} S_{\mathrm{F} 10}, S_{\mathrm{F} 11} S_{\mathrm{F} 11}, S_{1} S_{1}$ and $S_{2} S_{2}$ were homozygous for white flower colour and white pollen, with the exception of $S_{1} S_{1}$ which was heterozygous for red flower colour.

$\dagger S$-homozygous tester $S_{\mathrm{F} 1} S_{\mathrm{F} 1}$ was homozygous for white flower and white pollen.

Methods for collection, storage and irradiation of pollen, and for chromosome studies and the promotion of fruit set have been given previously (Pandey, 1979a). In all cases except where the self-compatible species $N$. langsdorffi was used as the female parent, the donor, irradiated pollen was mixed $(1: 1)$ with live, normal, self-incompatible pollen of the female parent before pollination. Normally, between 20 and 30 flowers were pollinated for each combination. In order to provide the best possible environment for germination and early growth, T1 seeds were sown on a sterile culture medium formulated by Butenko and Luneva (1966).

\section{(i) Progeny testing for gene transfer}

Plants of the T1 generation were tested for transfer of the $S$ gene from the donor parent and, in order to determine whether self-fertilisation had 
occurred, for the presence of one or both of the $S$ alleles from the maternal parent. Incompatibility in test crosses which failed to produce seed was confirmed by examination of pollen tube growth (Pandey, 1969). In addition to the $S$ gene, observations were made on transfer of the flower colour and pollen colour genes where applicable. Selfed and crossed T2 progenies were also tested for the presence of transferred genes.

\section{RESUlts AND Discussion}

\section{(i) Transformation of $\mathrm{N}$. alata 9151-2 with irradiated pollen} from $\mathrm{N}$. alata $8541-3$

Crosses and observations on T1 progeny are presented in table 2 . Observations on test crossed and selfed T2 progeny are shown in table 3. When two different $N$. alata donor parents were used with the same $N$. alata female parent, one $\mathrm{T} 1$ progeny consistently showed gene transfers while the other progeny showed none, although both donor plants were members of the same selfed progeny. However, a study of the T2 progeny of the group showing no gene transfers revealed that seven out of eleven plants examined were in fact carrying transferred genes but these had not been expressed in the T1 generation. Five of them carried both transferred $S$ and flower colour genes and one each carried a transferred $S$ or flower colour gene only.

TABLE 2

Observations on $T 1$ progeny of $\mathrm{N}$. alata and N. langsdorffii obtained through the use of irradiated pollen of $\mathrm{N}$. alata

\begin{tabular}{|c|c|c|c|c|c|}
\hline $\begin{array}{c}\text { Combination } \\
\text { No. }\end{array}$ & \multirow{2}{*}{$\begin{array}{c}\text { Female } \\
\text { parent } \\
9151-2 \\
9151-2\end{array}$} & \multirow{2}{*}{$\begin{array}{c}\begin{array}{c}\text { Irradiated, } \\
\text { donor } \\
\text { parent }\end{array} \\
\text { N. alata } 8541-3 \\
\text { N. alata } 8541-\mathrm{A}\end{array}$} & \multirow{2}{*}{$\begin{array}{c}\text { Total no. } \\
\text { of T1 } \\
\text { plants } \\
\text { studied } \\
47^{2} \\
13\end{array}$} & $\begin{array}{l}\text { No. of } \\
\text { plants with } \\
\text { expressed } S \\
\text { or flower } \\
\text { colour gene } \\
\text { transfer }\end{array}$ & $\begin{array}{l}\text { No. of } \\
\text { V.I. }{ }^{1} \\
\text { plants }\end{array}$ \\
\hline $\begin{array}{ll}\text { (1) } & \text { N. alata } \\
\text { (2) } & N . \text { alata }^{3} \\
\text { (3) } & \text { N. langsdor } \\
& \text { (self-compa }\end{array}$ & & & & $\begin{array}{r}0 \\
13\end{array}$ & $\begin{array}{l}9 \\
0\end{array}$ \\
\hline $\begin{array}{l}{ }_{1}^{1} \text { Defined in } \\
2 \text { From a tot } \\
{ }^{3} \text { Data from } \\
{ }^{4} \text { Arising fro } \\
{ }^{5} \text { In this con } \\
\text { presence of trans } \\
\text { species concerne } \\
\text { than those of the } \\
\text { normally inhibite } \\
\text { langsdorffi } N \text {. al } \\
\text { of a style contai } \\
\text { growth left no }\end{array}$ & $\begin{array}{l}\text { ants gro } \\
\text { s experi } \\
\text { there w } \\
\text { enes ow } \\
\text { he dono } \\
\text { arent } N \text {. } \\
\text { ne-third } \\
\text { tubes } w \\
\text { ransferr } \\
\text { he pres }\end{array}$ & $\begin{array}{l}\text { n from seeds ari } \\
\text { ent included for } \\
\text { some difficulty } \\
\text { g to a very large } \\
\text { parent } N \text {. alata } \\
\text { angsdorffii, and s } \\
\text { f the distance do } \\
\text { h an } S_{3} \text { allele we } \\
S_{3} \text { allele. How } \\
\text { ice of } S_{3} \text { allele }\end{array}$ & $\begin{array}{l}\text { g from } 9 \\
\text { nparison } \\
\text { the T1 g } \\
\text { ference in } \\
\text { flowers } v \\
\text { e the self- } \\
\text { their sty } \\
\text { ften able } \\
\text { er, the ov } \\
\text { incomp }\end{array}$ & $\begin{array}{l}\text { ls. } \\
\text { andey, } 197 \\
\text { eration in } \\
\text { e stylar len } \\
\text { ch are thre } \\
\text { llen tubes } \\
\text { it appeare } \\
\text { traverse th }\end{array}$ & $\begin{array}{l}1978 b) . \\
\text { ing for the } \\
\text { of the two } \\
\text { mes longer } \\
\text { t. alata are } \\
\text { at in T1 } N \text {. } \\
\text { hole length } \\
\text { ollen tube }\end{array}$ \\
\hline
\end{tabular}

A further difference between the two sets of progeny was the occurrence of 9 out of $47 \mathrm{~T} 1$ plants with the vegetative inflorescence (V.I.) character among the group showing no gene transfer, while no such plants occurred in the group in which gene transfer was observed, these plants occurring only in 


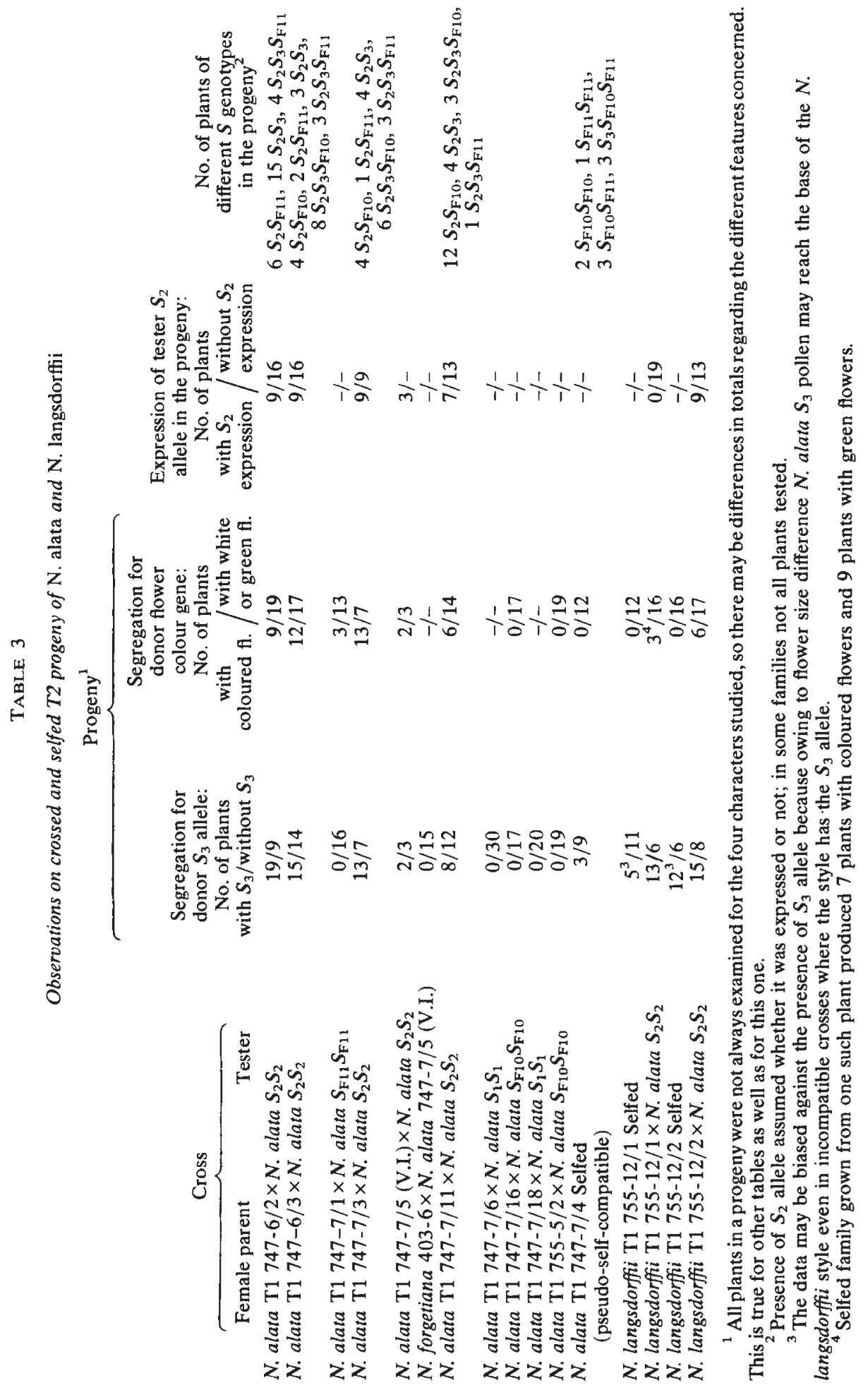


the T2 generation (Pandey, 1978b) (table 2). (In V.I. plants which were otherwise normal in appearance, the flower production was suppressed and the floral shoot became vegetative, with tufts of small leaves in place of flower buds.)

Another type of gene suppression was evident among the T2 generation of plants (table 3). This was the sporadic lack of expression of the $S_{2}$ gene contributed by the tester pollen parent $\left(S_{2} S_{2}\right)$. Normally all the progeny should express $S_{2}$. But in this case 86 out of 132 plants examined, in seven separate families, did not express $S_{2}$. (In the family $\stackrel{N}{N}$. langsdorffii $\mathrm{T} 1$ $755-12 / 1 \times N$. alata $S_{2} S_{2}$, none of the 19 plants showed expression of the $S_{2}$ allele.) Most, but not all, of these plants showed expression of the transferred gene $S_{3}$. The question arises: Under certain circumstances does the presence of a transferred $S$ allele suppress the action of other $S$ alleles even when present in the trans configuration? Interallelic complementation involving the regulatory elements of the $S$ complex has been previously reported in Oenothera and Nicotiana (Lewis, 1958; Pandey, 1967; Fincham and Sastry, 1974).

$S$ allelic examination of five T2 progenies (table 3 ) confirmed the previously reported observation that the transferred $S$ allele may occupy any of three proposed positions in the nucleus:

(1) Remain attached to the chromosome where it was first introduced, making this chromosome biallelic.

(2) The biallelic chromosome may lose the original maternal allele, giving a substituted monoallelic condition.

(3) The transferred gene may cross-over to the homologous chromosome thereby making that chromosome biallelic (Pandey, 1978b).

In four of the present crosses, where normal plants were used as males, and the nature of the male gametes was known, the $S$ allelic constitution of the progeny provided reasonable evidence for the $S$ gametic constitution of the female parent. The results, however, do not rule out the possibility that transferred chromatin may be attached at sites other than the homologous position on the chromosome.

It is also interesting to note that in the $\mathrm{T} 2$ progeny of the cross between the T1 V.I. plant 747-7/5 and a normal plant of $N$. alata or $N$. forgetiana, there is a reciprocal difference suggesting gametic selection. When the V.I. plant was used as the female parent two out of five plants in the T2 progeny contained the transferred $S_{3}$ allele while in the reciprocal cross, when the V.I. plant was used as the male parent, none of the $15 \mathrm{~T} 2$ plants contained the $S_{3}$ allele. Similar observations have been made before (Pandey, 1978b).

\section{(ii) Transformation of N. langsdorffii with irradiated pollen from N. alata alone}

In this experiment irradiated donor pollen from $N$. alata 8541-3 $\left(S_{3} S_{3}\right)$ was not mixed with living pollen of the self-compatible female parent. All five T1 plants examined appeared to carry a transferred $S_{3}$ gene (table 2), and this was subsequently confirmed by a study of $\mathrm{T} 2$ progenies from two $\mathrm{T} 1$ plants (table 3 ). Tests among the crossed and selfed $\mathrm{T} 2$ progenies showed that $S$ and flower colour genes were transferred in both the T1 plants tested although no evidence for transferred flower colour genes had appeared among the $\mathrm{T} 1$ plants themselves. 
The results for $N$. langsdorffii show that parthenogenetic diploidy and gametic transformation may occur without the aid of the mixed live pollen, although fewer viable seeds are produced.

\section{(iii) Transformation of $\mathrm{N}$. alata 9151-2 with irradiated pollen from $\mathrm{N}$. forgetiana 403-1, 403-2 or 403-6}

The observations on $\mathrm{T} 1$ plants obtained are given in table 4 . Of a total of 209 T1 plants tested 109 showed $S$ gene transfer. Of these 3 showed transfer of flower colour $+S$ gene, 11 , pollen colour $+S$ gene, and one showed transfer of all three characters, flower colour, pollen colour and $S$ gene. There were also 7 plants with transfer of flower colour alone and one where only pollen colour was transferred. Pollinations with only two of the three donor parents gave rise to V.I. plants. Apparently $S$ allelic constitution per se was not responsible for production of V.I. plants since, of the two donor plants, 403-1 and 403-6, having the same constitution $\left(S_{3} S_{5}\right)$, one produced V.I. plants and the other did not. Another point to note is that the appearance of V.I. plants in the T1 progeny was not necessarily associated with lack of expression of transferred genes, as was the case in the earlier experiment (table 2). In this experiment pollination with two donor plants gave V.I. plants as well as normal plants with expressed transferred genes.

Thirty T2 progenies (excluding two V.I. families), comprising 20 in which the transferred $S$ gene was expressed in the T1 generation and 10 in which there was no indication of $S$ transfer, were studied (table 5). There was one family in the latter group (fa. 971) where there were transfers of the $S$ gene and pollen colour gene which were not expressed in the T1 generation but expressed in the T2 generation. The T1 plant giving rise to this family belonged to the class of plants arising from the donor 403-1 which produced some V.I. plants. Six T2 families showed transfer of the pollen colour gene, none of which were identified in the $\mathrm{T} 1$ generation. In addition, ten T2 families showed transfer of the flower colour gene of which only one was expressed in the $\mathrm{T} 1$ generation. Thus, of the fifteen instances where a character appeared in the T2 generation but not in the T1 generation, with the exception of three (pollen colour, fams. 959, 962; flower colour, fa. 1070; donor 403-6), all had originated in experiments where plants 403-1 or 403-2 were used as donors, and which had also given rise to V.I. plants. Normal crosses between the original female parent ( $N$. alata 9151-2) and the tester used in these crosses ( $N$. forgetiana $\left.S_{\mathrm{F} 1} S_{\mathrm{F} 1}\right)$ have not produced, among 32 plants grown, a single plant having coloured flowers or coloured pollen. Another significant point is that in two families, 972 and 964 (table 5), almost all plants (32 out of 33) contained the transferred $S$ gene. In the previous study also, there were a number of families showing strong gametic selection in favour of $S$ gene transfer (Pandey, 1975 $b, 1978 b$ ). In all cases where the transferred genes were expressed in the $\mathrm{T} 1$ generation, they were also expressed in the $\mathrm{T} 2$ generation.

\section{(iv) Transformation of $\mathrm{N}$. forgetiana 403-5 with irradiated pollen from $\mathrm{N}$. alata 9151-2}

In this combination no V.I. plants were produced in the T1 progeny (table 4). Of a total of $42 \mathrm{~T} 1$ plants tested, 17 showed transfer of the $S_{\mathrm{F} 10}$ 
TRANSFORMATION IN NICOTIANA

A

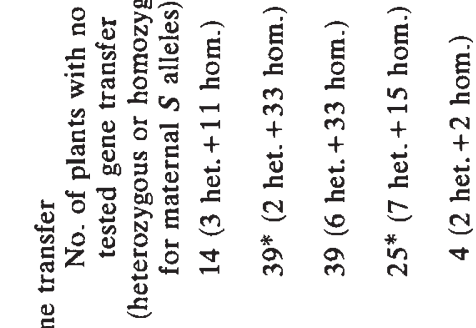

苍嵒苛

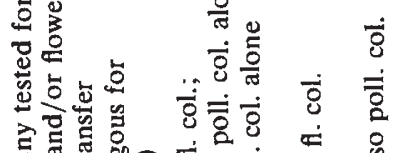

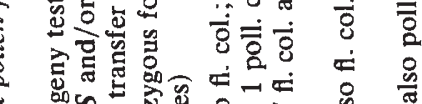

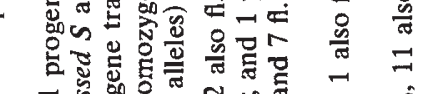

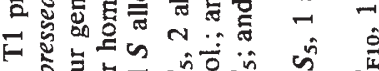

हैँ

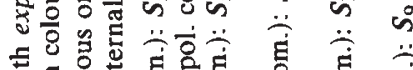

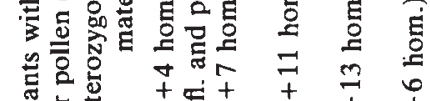

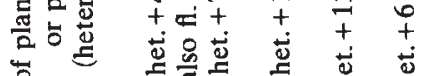

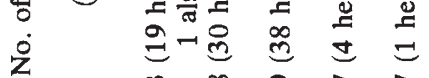

造

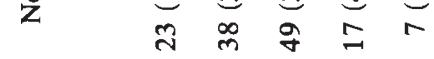

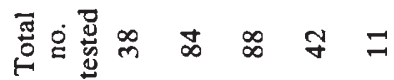

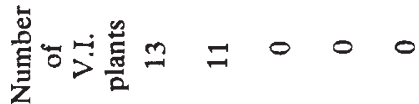

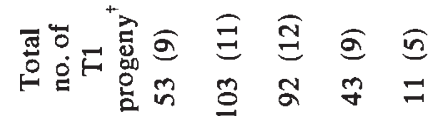

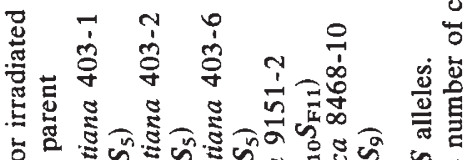

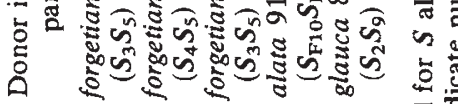

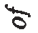

密 z z z z z 无

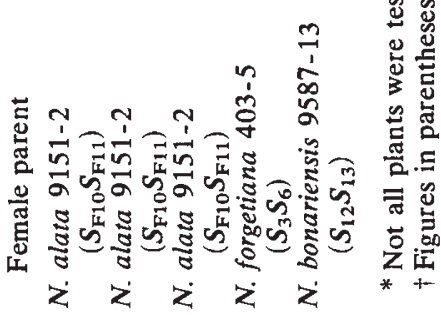


TABle 5

Observations on $T 2$ progeny of $\mathrm{N}$. alata and $\mathrm{N}$. forgetiana ( $T 1$ plants $\times ð$ Normal $\mathrm{N}$. forgetiana $S_{\mathrm{F} 1} S_{\mathrm{F} 1}$ )

Original
pollination

q parent

N. alata 9151-2

$\left(\mathrm{S}_{\mathrm{F} 10} S_{\mathrm{F} 11}\right)$

$\delta$-irradiated donor

N. forgetiana 403-1

$\left(S_{3} S_{5}\right)$
N. alata 9151-2

$\left(S_{\text {F10 }} / S_{\text {F11 }}\right)$ $\delta$-irradiated donor

N. forgetiana

403-2 $\left(S_{4} S_{5}\right)$

$\$$ parent

N. alata 9151-2

$\left(S_{\mathrm{F} 10} / S_{\mathrm{F} 11}\right)$

$\delta$-irradiated donor

N. forgetiana 403-6

$\left(S_{3} S_{5}\right)$

parent
$\quad$. forgetiana $403-5$
$\quad\left(S_{3} S_{5}\right)$

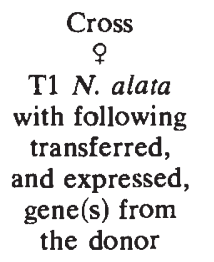

Family
no.


$972^{1}$
1073
963
970
971
973

$\begin{array}{lr}S_{5} & 964 \\ S_{5} & 966 \\ S_{5} & 1064 \\ S_{5} & 1071 \\ S_{5} & 1072\end{array}$

$S_{5}$ and fl. col. 1075

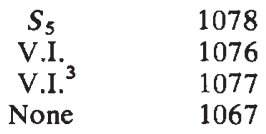

None $\quad 1074$

$\begin{array}{ll}S_{5} & 954 \\ S_{5} & 955 \\ S_{5} & 956 \\ S_{5} & 957 \\ S_{5} & 958 \\ S_{5} & 959 \\ S_{5} & 960\end{array}$

$\begin{array}{ll}S_{5} & 962 \\ S_{5} & 968\end{array}$

$\begin{array}{ll}S_{5} & 1068\end{array}$

$\begin{array}{ll}S_{5} & 1070\end{array}$

None $\quad 961$

None $\quad 967$

None $\quad 977$

None $\quad 1069$

$S_{\mathrm{F} 10}{ }^{4} \quad 969$

$S_{\mathrm{F} 10} \quad 974$

$\begin{array}{ll}S_{\mathrm{F} 10} & 978\end{array}$

$S_{\mathrm{F} 10} \quad 979$

$S_{\mathrm{F} 10}{ }^{4} \quad 985$

$S_{\mathrm{F} 10}{ }^{4} \quad 986$

T2 progeny

$S$ gene:

No. of plants

with and without

transferred allele

with $S_{5}$ /

without $S_{3}$ or $S_{5}$

$19 / 1$

$7 / 5$

$0 / 19$

$0 / 19$

$6 / 14$

$0 / 2$

with $S_{5} /$

without $S_{4}$ or $S_{5}$

$\begin{array}{cll}12^{2} / 0 & 0 / 12 & 0 / 12 \\ 4 / 2 & 0 / 6 & 0 / 12 \\ 4 / 3 & 2 / 5 & 0 / 7 \\ 12 / 7 & 2 / 17 & 2 / 17 \\ 7 / 11 & 8 / 10 & 0 / 18 \\ & & \\ 8 / 6 & 10 / 4 & 0 / 14 \\ 5 / 11 & 1 / 15 & 0 / 16 \\ 4 / 4 & 1 / 7 & 0 / 8 \\ 4 / 11 & 6 / 9 & 0 / 15 \\ 0 / 12 & 0 / 12 & 0 / 12 \\ 0 / 14 & 0 / 14 & 0 / 14\end{array}$

with $S_{5} /$

without $S_{3}$ or $S_{5}$

$\begin{array}{cll}9 / 11 & 0 / 20 & 0 / 20 \\ 5 / 4 & 0 / 9 & 0 / 9 \\ 11 / 7 & 0 / 18 & 0 / 18 \\ 2 / 1 & 0 / 3 & 0 / 3 \\ 9 / 4 & 0 / 13 & 0 / 13 \\ 9 / 8 & 0 / 17 & 1 / 16 \\ 5 / 2 & 0 / 7 & 0 / 7 \\ & & \\ 11 / 9 & 0 / 20 & 6 / 14 \\ 3 / 7 & 0 / 10 & 0 / 10 \\ 5 / 8 & 0 / 13 & 0 / 13 \\ 8 / 6 & 4 / 10 & 0 / 14 \\ 0 / 20 & 0 / 20 & 0 / 20 \\ 0 / 5 & 0 / 5 & 0 / 5 \\ 0 / 11 & 0 / 11 & 0 / 11 \\ 0 / 15 & 0 / 15 & 0 / 15\end{array}$

with $S_{\mathrm{F} 10} /$

without $S_{\mathrm{F} 10}$ or $S_{\mathrm{F} 11}$

$\begin{array}{lcc}2 / 2 & - & 0 / 4 \\ 7 / 10 & - & - \\ 1 / 1 & - & 0 / 2 \\ 10 / 9 & - & - \\ 13 / 5 & - & 0 / 18 \\ 10 / 7 & - & 0 / 17\end{array}$


TABLE 5 (cont.)

$\begin{array}{cccc}8 \text {-irradiated donor } & S_{\mathrm{F} 10} & 987 & 10 / 10 \\ N . \text { alata } 9151-2 & \text { None } & 975 & 0 / 3 \\ \left(S_{\mathrm{F} 10} S_{\mathrm{F} 11}\right) & \text { None } & 976 & 0 / 19 \\ & \text { None } & 980 & 0 / 20 \\ & \text { None } & 981 & 0 / 15 \\ & \text { None } & 982 & 0 / 6 \\ & \text { None } & 983 & 0 / 6 \\ & \text { None } & 984 & 0 / 18\end{array}$

${ }^{1}$ The T1 plant did not express transferred flower colour or pollen collour genes, only the $S_{5}$ gene. T2 progeny showed transfer of all three characters. Among the segregants there was one plant, the only one in the family, which had transferred flower colour gene but no $S$ or pollen colour gene; one plant with transferred flower colour gene and $S$ gene but no pollen colour gene; and one plant with all three, flower colour, pollen colour and $S$ genes. Similarly, there were five other T2 families $(962,970,971,1071,1078)$ showing transferred characters which were not expressed in the respective T1 plants.

${ }^{2}$ Extreme gametic selection, all plants having the transferred allele $S_{5}$.

${ }^{3}$ The parent T1 V.I. plant showed flower colour gene transfer in the rare mutilated flowers, the T2 progeny (in this case, a result of cross T1 $\times N$. alata $S_{2} S_{2}$ ) showed the presence of transferred $S_{5}$ allele as well as flower colour gene.

${ }^{4} \mathrm{~T} 1$ plant showed blue pollen colour, not present in either of the two parents.

gene, 11 of which also showed transfer of the pollen colour gene. Brieger (1935) has shown that pollen colour in Nicotiana is controlled by two independent complementary genes. In the present study, since both female parent and donor bred true for white pollen colour, the appearance of blue pollen colour in the T1 progeny was apparently due to transfer of a complementary gene from $N$. alata. This conclusion was further supported by the fact that none of the four T2 progenies from these plants contained plants with blue pollen (fams. 969, 978, 985, 986; table 5).

Since all 11 plants with pollen colour transfer also showed transfer of the $S_{\mathrm{F} 10}$ gene, and the proportion $(11 / 17)$ of these plants among the total T1 plants showing transfer of the $S$ gene is very high, this suggests that the complementary gene for pollen colour may be linked with the $S_{\mathrm{F} 10}$ locus. This is in agreement with the conclusion of Brieger (1935), that the $S$ gene is linked with the basic anthocyanin colour factor $C$, and one of the factors for blue pollen colour, $B_{1}$. The linkage between $S$ and $C$ is loose $(20$ per cent recombination) but that between $C$ and $B_{1}$ is very close $(0.5$ per cent). Brieger also identified a flower colour factor $R$ which is independent of this linkage group. The obvious close relationship between the transformation pattern and genetic linkage is interesting, and may be indicative of the size of individual transferred DNA molecules.

As regards transfer of the $S$ gene, the behaviour of the 14 T2 progenies fully confirmed the observations on the $\mathrm{T} 1$ generation (table 5). The seven families in which the T1 parent showed transfer of the $S_{\mathrm{F} 10}$ gene segregated for the $S_{\mathrm{F} 10}$ gene as expected, the other seven families in which the T1 parent had shown no transfer of the $S$ gene showed no evidence of $S_{\mathrm{F} 10}$ in the progeny.

(v) Transformation of N. bonariensis 9587-13 with irradiated pollen from $\mathrm{N}$. glauca $8468-10$

Seven out of $11 \mathrm{~T} 1$ plants produced from this combination showed transfer of the $S_{2}$ allele from $N$. glauca. None showed transfer of the flower colour gene (table 4). 
A total of $93 \mathrm{~T} 2$ plants grown from crosses of five $\mathrm{T} 1$ plants having transfer of the $S$ gene gave rise to 11 diminutive, sterile (D.S.) plants in which the floral inflorescence was very much stunted and nearly all buds dropped before maturity (D.S./total No. of plants: $4 / 21,3 / 20,4 / 22,1 / 20$, $0 / 10$ ) (fig. 1). In certain D.S. plants rare buds did reach maturity and produced nearly normal flowers. D.S. plants are comparable with V.I. plants arising in the T1 and T2 progenies of $q N$. alata $\times N$. alata donor and i $N$. alata $\times N$. forgetiana donor combinations.

\section{(vi) Cytology of $T 1$ plants}

Six T1 plants from each of the five species combinations were examined for meiosis in the anthers. They revealed no significant chromosomal abnormalities. They all had the regular $2 n=18$ chromosomes of the female parents and no fragments. All plants had high pollen fertility (70-95 per cent).

The fact that in the combination $N$. bonariensis $q(2 n=18) \times N$. glauca donor $(2 n=24)$ the T1 plants had the chromosome complement of the female parent $(2 n=18)$ and not that of a hybrid $(2 n=21)$, proved that no true fertilisation by a live male gamete had been involved in production of $\mathrm{T} 1$ embryos. True hybrids between these two species have been produced in our laboratory. They have never shown post-zygotic chromosome elimination or modification, their vegetative and.foral characteristics are very distinct from either of the parents, and they are completely sterile. The transfer of the $S_{2}$ gene from the donor $N$. glauca to the recipient female parent $N$. bonariensis can, therefore, reasonably be attributed to gametic transformation of the egg as proposed. Indeed, the consistently maternal appearance of the $\mathrm{T} 1$ plants in all experiments showing gene transfer, including three interspecific combinations, leaves no doubt regarding the authenticity of the phenomenon of egg transformation. There is no other conceivable way by which such gene transfers between distinct species could occur without normal sexual union.

\section{(vii) S gene complex and egg transformation}

There are two intriguing aspects of the egg transformation phenomenon emerging from the present observations:

\section{(a) S gene selection}

There is a general specificity in favour of the $S$ gene in transformation. Thus out of a total of $262 \mathrm{~T} 1$ plants examined in the five combinations summarised in table 4,133 , approximately 50 per cent, showed $S$ gene transfer, whereas only 11 showed flower colour and 20 , pollen colour gene transfers. Significantly, all 5, rare, T1 plants produced through parthenogenetic diploidy in $N$. langsdorffii showed $S$ gene transfers.

\section{(b) $\mathrm{S}$ allele selection}

There is also absolute allelic specificity regarding $S$ gene transfer. Without exception, all of the $110 \mathrm{~T} 1$ alata plants derived from the three 


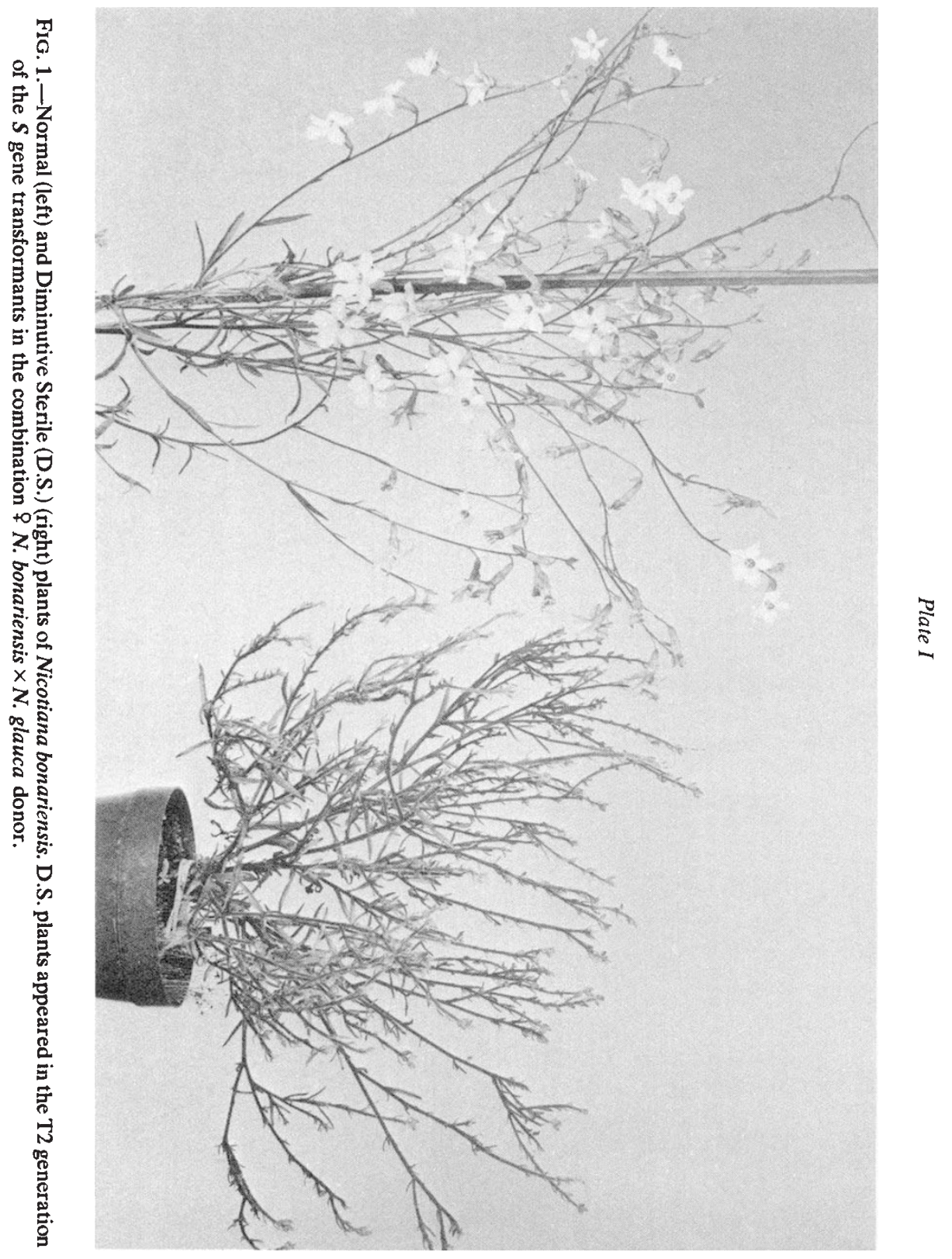


donor forgetiana plants, two having the constitution $S_{3} S_{5}$ and one $S_{4} S_{5}$, showed transfer of the $S_{5}$ allele only. None of the T1 plants showed transfer of the sister alleles $S_{3}$ or $S_{4}$. Similarly, in all 17 cases of $S$ gene transfer to forgetiana from alata $\left(S_{\mathrm{F} 10} S_{\mathrm{F} 11}\right)$, it was the $S_{\mathrm{F} 10}$ allele only which was transferred, there being no transfer of the sister allele $S_{\text {F11 }}$ (table 4 ).

What could be the basis of such a close relationship between the $S$ gene and transformants and such extreme allelic specificity in gene transfers? Recently it has been proposed (Pandey, 1979a) that a number of embryo growth-promoting genes of varying potency may be present in the genome and in particular one such gene of a relatively high potency may be linked with the $S$ locus. Thus all 5 rare parthenogenetic seedlings obtained though pseudofertilisation by irradiated pollen alone in $N$. langsdorffii showed $S$ gene transformation. This $S$-linked gene may have a number of allelic forms, some competent, others incompetent in the promotion of embryo growth. Only those $S$ alleles which are associated with the competent allele will be effective in promoting normal embryo growth and recovery of the seed with specific $S$ allele transformation.

Although an overwhelming proportion of transformed plants contained the $S$ gene transfer, either alone or in association with transferred flower or pollen colour genes, there was a small proportion of transformants which had no $S$ gene transfer (table 4). All T1 plants showing flower colour transformation alone have appeared in combinations where there was a mixed pollination and seed was usually produced through a second normal fertilisation, the result of a weak mentor pollen effect on slower growing self pollen (table 4, and Pandey, 1978b). Thus in these combinations, presumably ovules which had been partly stimulated as a result of transformation by the embryo growth-promoting gene, either linked with the flower colour gene or independently but simultaneously transferred, were rescued by the second, normal fertilisation. Even those T1 plants which did not show transfer of any of the three genes studied may, hence, have contained transferred partly potent embryo growth-promoting genes which allowed their embryos to be rescued by the second fertilisation. The use of irradiated pollen, in certain cases combined with the mentor pollen effect, could thus act as a selection sieve to identify genes promoting embryo growth after pseudofertilisation. It may then be possible to combine several such genes and synthesise genotypes which would have a tendency to produce a high frequency of parthenogenetic diploids.

\section{(viii) Mentor pollen effect}

$S$ allelic tests on T1 plants in the present series of experiments (table 6) showed that self-fertilisation as a result of a weak mentor pollen effect was quite common in most Nicotiana plants used as female parents. More than 50 per cent of the $\mathrm{T} 1$ plants tested had identifiable gene transfers (table 4). Thus, it would appear that a large proportion of $\mathrm{T} 1$ plants resulted from two fertilisations, first by irradiated mentor pollen causing egg transformation, and then later by self-pollen. After pollination with a mixture of irradiated compatible pollen and normal, live, incompatible pollen, three types of seed development are possible:

(1) There may be no mentor pollen effect to overcome the incompatibility of the live pollen. In this case any seeds produced would arise by 
TABLE 6

Observations on $T 1$ plants showing the extent of self-fertilisation as opposed to parthenogenetic diploidy ${ }^{1}$

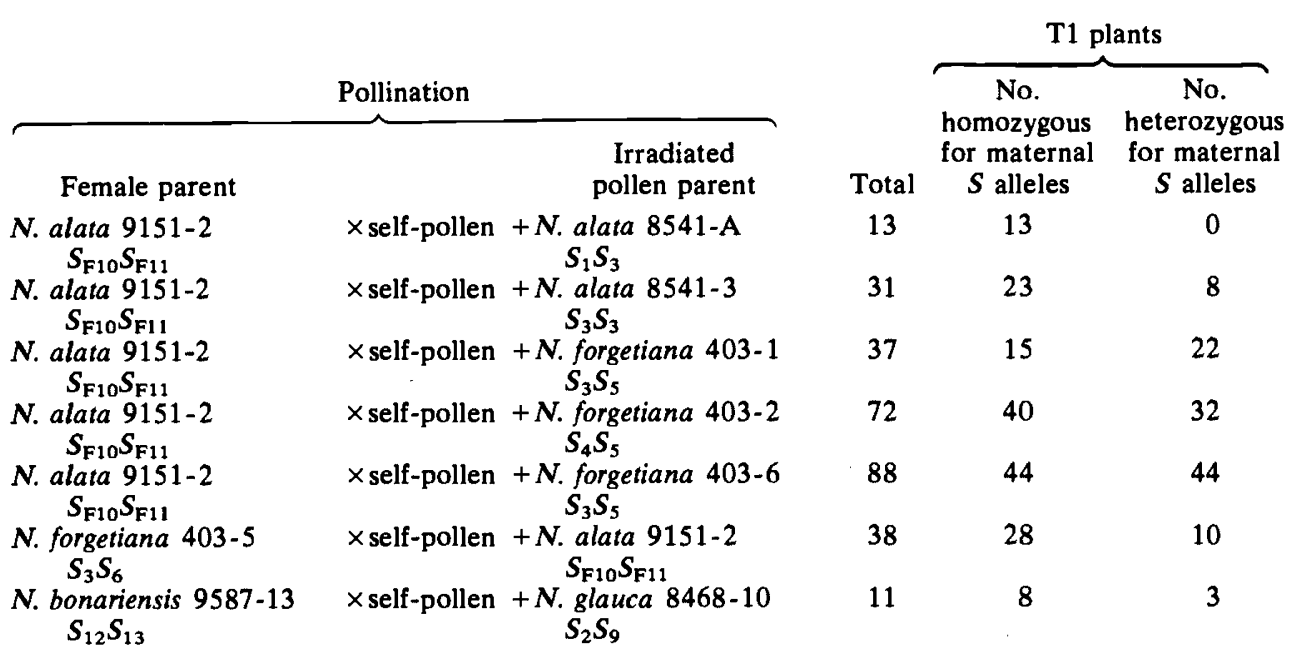

${ }^{1}$ Families having only $S$ homozygous plants arose from parthenogenetic diploidy (the first combination in the table); families having both $S$ homozygous and heterozygous plants resulted from selfed seed but may also have plants arisen from parthenogenetic diploidy (all other combinations).

parthenogenetic diploidy after pseudofertilisation by irradiated pollen alone, and would be likely to have arisen by egg transformation and selective stimulation ((2), table 2).

(2) There may be a weak mentor pollen effect, allowing a few incompatible, live pollen tubes to grow slowly and eventually reach the embryo-sac, after pseudofertilisation by compatible irradiated pollen has already occurred. Most of the ovules would have been "sterilised" by a preceding pseudofertilisation but some, presumably owing to transformations involving embryo growth-promoting genes, might be capable of accepting a second fertilisation to produce a normal diploid seed. In this case only a small number of seeds are set, and the weak mentor pollen effect is beneficial for it enhances the recovery of eggs transformed for embryo growthpromoting genes, particularly those which are insufficiently stimulated and might otherwise not be recovered. However, with the rise in the number of seeds through self-fertilisations, the proportion of T1 plants with $S$ gene transfer declines (table 4).

(3) There may be a highly efficient mentor pollen effect, making the incompatible pollen behave as compatible (Pandey, 1978c, 1979b). In this case the live, now compatible, pollen may compete successfully with the irradiated compatible pollen and reach the ovules first. Normally fertilised embryo-sacs would not allow a second fertilisation by the later arriving irradiated pollen, and would thus produce only normal seeds without transformation. Any comparatively slow-growing transformed embryo that might have resulted from an initial pseudofertilisation would be disadvantaged by the large numbers of vigorously growing normal embryos in the same ovary. Under such circumstances, although a large number of seeds would be produced these would be unlikely to contain transformations. Thus, the mentor pollen effect can be an aid to the practical 
application of egg transformation only where it is relatively weak, allowing only a few normal, second fertilisations to occur. The fact that in the present experiments the efficiency of mentor pollen effect has generally been of this order has been a significant factor in the elucidation of the relationship between mentor pollen effect and egg transformation.

\section{(ix) Use of the $\mathrm{S}$ locus as a selection marker in egg transformation by irradiated pollen}

It is obvious from the above observations that the use of a self-incompatible donor, providing an $S$ locus, with which a major gene promoting embryo growth is closely linked, has been the key to success of the egg transformation work. When the recipient and donor are both selfincompatible, recovery of transformed seeds can be enhanced with the aid of a second, normal fertilisation by self-pollen, facilitated by the mentor pollen effect.

Since the transferred gene in many cases is not expressed in the T1 generation but only in the following sexual generation, it becomes necessary that $\mathrm{T} 2$ progenies be examined from each $\mathrm{T} 1$ plant. This may become an impractical proposition if the number of $\mathrm{T} 1$ seeds is too large and the prospect of recovering transformed seedlings from them too low. Any technique which ensures that all the T1 seedlings obtained have in fact undergone genetic transformation would be advantageous. Combinations in which pollen of a self-incompatible species is used as a donor and there is no mixture of pollen from the self-incompatible female parent, offer this possibility. All such T1 seedlings should be the result of parthenogenetic diploidy and would be expected to have a transferred $S$ gene. It is reasonable to assume that in any transformed seed the transferred $S$ locus would be only one of many genes transferred together in one act of pseudofertilisation. The ability of a growth factor linked with the $S$ locus to rescue transformed embryos is therefore highly significant. The $S$ locus may thus be employed as a selection marker in egg transformation where the donor is self-incompatible. This feature is even more significant for combinations where the female, recipient, parent is self-compatible, for in such cases this is the only way transformed viable seed could be obtained. The use of embryo and ovule culture may boost the number of $\mathrm{T} 1$ progeny recoverable by this technique.

\section{CONCLUSIONS AND FUTURE PROSPECTS}

There are two main limitations to the wide practical application of egg transformation at present. One is the necessity for donor pollen to be able to germinate, grow and discharge its contents within the recipient pistil. In nature growth of foreign pollen is normally hampered by pollen-pistil incompatibility, particularly in distantly related plants. However, certain recent observations suggest that for appropriate combinations of female and pollen parents the "mentor pollen effect" may make egg transformation feasible in situations where normal sexual hybridisation is impossible (Pandey, 1979b). Alternatively, in certain favourable materials in vitro fertilisation, or direct injection of a suspension of donor pollen into the 
ovary, combined with ovary or ovule culture techniques, may overcome pollen-style incompatibility.

Another limitation to egg transformation is the relatively rare development of seeds through parthenogenetic diploidy after pseudofertilisation by irradiated pollen. However, the finding that certain $S$ alleles may be linked with a major gene which promotes growth of the $S$ transformed eggs into viable embryos is highly significant. It would allow the possibility, in a combination where the donor is self-incompatible, for the $S$ locus to be used as a selection marker to rescue transformed embryos which otherwise would not be recovered. Application of hormones and embryo culture may also be helpful in promoting parthenogenesis and recovering transformed seed.

It is possible that the technique might be used to convert a presently self-compatible species into a self-incompatible one by incorporating $S$ alleles from related self-incompatible species of the same genus. With regard to plant improvement in general, egg transformation offers a potentially rapid method for transferring specific genes without recurrent backcrossing. By breaking down linkage relationships the technique may allow selective transfer of desirable genes alone from relatively distantly related species. However, there is still much work to be done in developing this technique, and in elucidating the molecular and physiological mechanisms which underlie this phenomenon.

Acknowledgements.-I thank Mr G. B. Petterson and Miss Janet Plummer for able technical assistance, and Mr R. J. Trott, Physicist, Palmerston North Hospital, for his help in the irradiation of pollen.

\section{REFERENCES}

BRIEGER, F. G. 1935. Genetic analysis of the cross between the self-fertile Nicotiana langsdorffi and the self-sterile N. sandarae. J. Genet., 30, 78-100.

BUTENKO, R. G., AND LUNEVA, M. Z. 1966. The application of the sterile culture technique for the cultivation of distant hybrids of Nicotiana. Fiziol. Rast., 13, 733-736.

COCKING, E. C. 1977. Genetic modification of plant cells: a reappraisal. Nature, 266, 13-14.

FINCHAM, J. R. S., AND SASTRY, G. R. K. 1974. Controlling elements in maize. Ann. Rev. Genet., 8, 15-50.

HESS, D. 1977. Cell modification by DNA uptake. In Plant Cell, Tissue and Organ Culture, eds. J. Reinert and Y. P. S. Bajaj, pp. 506-577. Springer-Verlag, Berlin-Heidelberg.

LEWIS, D. 1958. Gene control of specificity and activity: Loss by mutation and restoration by complementation. Nature, 182, 1620-1621.

LURQUIN, P. F. 1977. Integration versus degradation of exogenous DNA in plants: An open question. In Progress in Nucleic Acid Research and Molecular Biology, vol. 20, ed. W. E. Cohn, pp. 161-207. Academic Press, New York.

PANDEY, K. K. 1963. Stigmatic secretion and bud-pollinations in self- and cross-incompatible plants. Naturwissenschaften, 50, 408-409.

PANDEY, K. K. 1967. Elements of the $S$-gene complex II. Mutation and complementation at the $S_{\mathrm{I}}$ locus in Nicotiana alata. Heredity, 22, 255-283.

PANDEY, K. K. 1969. Elements of the $S$-gene complex V. Interspecific cross-compatibility relationships and theory of the evolution of the $S$ complex. Genetica, 40, 447-474.

PANDEY, K. K. 1973. Phases in the $S$ gene expression, and $S$-allele interaction in the control of interspecific incompatibility. Heredity, 31, 381-400.

PANDEY, K. K. 1975a. Sexual transfer of specific genes without gametic fusion. Nature, 256, 310-313.

PANDEY, K. K. 1975 b. Transformation, incompatibility and plant improvement. Incompatibility Newsletter No. 6, 91-121.

PANDEY, K. K. 1976. Genetic transformation and "graft-hybridization" in flowering plants. Theor. Appl. Genet., 47, 299-302. 
PANDEY, K. K. 1977. Genetic control of interspecific incompatibility between Nicotiana alata and $N$. langsdorffii: Correction of Takahashi's observations. Japan. J. Genet., 52, 431-433.

PANDEY, K. K. 1978a. Novel techniques of gene transfer and plant improvement: An appraisal of transformation in eukaryotes. New Phytol., 81, 685-705.

PANDEY, K. K. 1978b. Gametic gene transfer in Nicotiana by means of irradiated pollen. Genetica, 49, 53-69.

PANDEY, K. K. 1978c. Proposed causal mechanisms of the "mentor pollen effect". Incompatibility Newsletter No. 10, 87-93.

PANDEY, K. K. 1979a. Parthenogenetic diploidy and egg transformation induced by irradiated pollen in Nicotiana. N.Z.J. Bot., 18 (in press).

PANDEY, K. K. $1979 b$. Overcoming incompatibility and promoting genetic recombination in flowering plants. In Proc. Symp. "Reproduction in Flowering Plants". Christchurch, New Zealand, N.Z. J. Bot., 17, 645-663.

VIRK, D. S., DHAHI, S. J., AND BRUMPTON, R. J. 1977. Matromorphy in Nicotiana rustica. Heredity, 39, 287-295. 